\title{
Prediction of Global Solar Radiation in Abu Dhabi
}

\author{
Ali Assi, Mohammed Jama, and Maitha Al-Shamisi \\ Electrical Engineering Department, United Arab Emirates University, P.O. Box 71555, Al Ain, UAE \\ Correspondence should be addressed to Ali Assi, ali.assi@uaeu.ac.ae
}

Received 27 November 2011; Accepted 28 December 2011

Academic Editors: H. K. Ozturk and P. Tsilingiris

Copyright ( 12012 Ali Assi et al. This is an open access article distributed under the Creative Commons Attribution License, which permits unrestricted use, distribution, and reproduction in any medium, provided the original work is properly cited.

\begin{abstract}
Mathematical expressions have been employed to estimate global solar radiation on horizontal from relative sunshine duration for two weather stations in the United Arab Emirates (UAE), which are Abu Dhabi and Al Ain. These expressions include the original Angstrom-Prescott regression function (linear), quadratic function, third-order function, single-term exponential function, power function, logarithmic, and linear-logarithmic function. The predicted values were compared to the measured values using number of statistical methods to validate the goodness of the fits, such as residual analysis and goodness of fit statistics. All the used mathematical models performed generally well in both cities of Abu Dhabi and Al Ain, with all values of the coefficient of determination $\left(R^{2}\right)$ higher than $75 \%$. Specifically, the linear Angstrom-Prescott model estimated the average monthly global radiation on horizontal best for the city of Abu Dhabi, providing the second lowest mean absolute percentage error (MAPE) of $1.89 \%$ and the highest value of $R^{2}$, which is approximately $94 \%$, while the third-order model proved to be the best estimator for the city of $\mathrm{Al}$ Ain, providing the lowest MAPE value (3.06\%) and a corresponding $R^{2}$ of $83 \%$.
\end{abstract}

\section{Introduction}

Solar radiation is a primary factor in many applications, such as solar energy systems, architecture, agriculture, and irrigation. Despite the significance of solar radiation measurements, they are not yet available everywhere in the world. Due to the cost and maintenance and calibration requirements, this information is not readily available in many developing countries [1]. Therefore, it is of great importance to propose an efficient alternative to be used as a solar radiation estimator based on other more readily available meteorological data. Several empirical models for calculating solar radiation have been suggested in the literature. Some of these models use variables like sun hours, air temperature, relative humidity, and cloudiness. The most widely used parameter to estimate solar radiation is sunshine duration, which can be easily and reliably measured [2]. Angstrom regression model is the most commonly used method, which is a linear correlation between the average daily global radiation to the corresponding value on a completely clear day and the ratio of average daily sunshine duration to the maximum possible sunshine duration. Prescott suggested replacing the clear sky global radiation with the extraterrestrial radiation, producing a more convenient form of Angstrom equation called Angstrom-Prescott regression model [3,4].

In [5], the daily diffuse solar radiation was estimated using Liu and Jordan method, while number of correlations for different periods of the day proved to give better fit to estimate hourly diffuse solar radiation on horizontal. In [6], several empirical correlations were utilized to estimate the global monthly solar radiation on horizontal for number of provinces in Turkey, while in [7] a generic correlation was developed to calculate the daily diffuse solar radiation based on Liu and Jordan methodology. Similar study was conducted by [8], where the Angstrom-Prescott linear regression model and its quadratic and cubic derivatives were used to estimate the global monthly solar radiation for five different Egyptian provinces.

The potential of solar radiation in UAE is significant, with an average annual solar hours of $3568 \mathrm{~h}$ (i.e., $9.7 \mathrm{~h} /$ day), which corresponds to an average annual solar radiation of approximately $2285 \mathrm{kWh} / \mathrm{m}^{2}$ (i.e., $6.3 \mathrm{kWh} / \mathrm{m}^{2}$ per day) [9]. In this work, a number of regression models were investigated and validated to estimate monthly average daily global radiation on horizontal using only sunshine duration measurements for both cities of Abu Dhabi and Al-Ain 


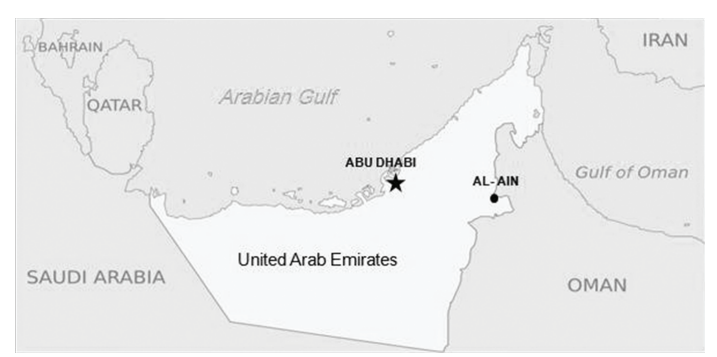

Figure 1: UAE map showing the location of Abu Dhabi and Al Ain.

geographically situated as shown in Figure 1. To choose the most adequate model, all models have been tested using statistical methods. The meteorological data used in this work were provided by the National Center of Meteorology and Seismology (Abu Dhabi) for the periods between 1995 and 2007. MATLAB tool was used to obtain and validate the regression models.

\section{Theory}

Several types of regression models have been proposed in the literature for predicting global solar irradiance on horizontal from the daily sunshine hours and extraterrestrial solar radiation. Table 1 shows the regression models used in this study. The regression models in Table 1 are given in terms of the clearness index; $K_{T}=G / G_{o}$ is the ratio of the monthly average daily global radiation on horizontal and its corresponding extraterrestrial radiation, and the other variable is the sunshine duration ratio $\left(R_{s}\right)$, which is the ratio between measured daily sun hours $(S)$ and theoretical maximum daily sun hours $\left(S_{o}\right)$. The daily extraterrestrial solar radiation on horizontal can be calculated as shown in

$$
\begin{aligned}
G_{o} & =\frac{24}{\pi} G_{\mathrm{SC}}\left(1+0.033 \cos \left(\frac{2 \pi d_{n}}{365}\right)\right) \\
& \times\left(\cos \phi \cos \delta \sin \omega_{S}+\omega_{S} \sin \phi \sin \delta\right),
\end{aligned}
$$

where $G_{s c}$ is the solar constant and is approximately $1.367 \mathrm{~kW} / \mathrm{m}^{2}[10], d_{n}$ is number of the day in the year, $\varphi$ is the site latitude, $\delta$ is the solar declination angle computed using (2) [10], and $\omega_{s}$ is the daily sun rise hour computed using (3). While $S_{o}$ can be computed using (4) [7]

$$
\begin{gathered}
\delta=23.45 \sin \left(\frac{360\left(284+d_{n}\right)}{365}\right), \\
\omega_{S}=\cos ^{-1}(-\tan \phi \tan \delta), \\
S_{o}=\frac{2}{15} \omega_{s} .
\end{gathered}
$$

As shown in Table 1, the objective of this study is to determine the regression coefficients of the seven regression models, which are " $a$ ", " $b$ ", " $c$ ", and " $d$ ". Each of these coefficients gives an indication about the solar radiation characteristics for the location under investigation. For
TABLE 1: Regression models used in this paper.

\begin{tabular}{ll}
\hline Model (source) & Regression model \\
\hline $\begin{array}{l}\text { Linear (Angstrom-Prescott } \\
[3,4])\end{array}$ & $K_{T}=a+b R_{S}$ \\
$\begin{array}{l}\text { Quadratic (Akinoglu and Ecevit } \\
[11])\end{array}$ & $K_{T}=a+b R_{S}+c R_{S}{ }^{2}$ \\
$\begin{array}{l}\text { Third order (Samuel [12]) } \\
\text { Logarithmic (Ampratwum and }\end{array}$ & $K_{T}=a+b R_{S}+c R_{S}{ }^{2}+d R_{S}{ }^{3}$ \\
$\begin{array}{l}\text { Dorvlo [13]) } \\
\text { Linear-logarithmic (Newland }\end{array}$ & $K_{T}=a+b \log \left(R_{S}\right)$ \\
$\begin{array}{l}\text { [14]) } \\
\text { Exponential (Elagib and Monsell } \\
[15])\end{array}$ & $K_{T}=a+b R_{S}+c \log \left(R_{S}\right)$ \\
Power (Coppolino [16]) & $K_{T}=a e^{(\mathrm{bR})} S$ \\
\hline
\end{tabular}

example, in the modified linear Angstrom-Prescott model, the regression parameter " $a$ " is a measure of the overall atmospheric transmission for total cloud conditions, while the parameter " $b$ " represents the rate of change of $G / G_{o}$ with respect to $S / S_{o}[6]$.

\section{Methodology}

The main objective of this research work is to obtain the correlation coefficients for seven different regression models for Abu Dhabi and $\mathrm{Al}$ Ain. To produce the regression equations, daily weather data for Abu Dhabi (Latitude: $23.5^{\circ} \mathrm{N}$, Longitude: $54.5^{\circ} \mathrm{E}$, and Elevation: $6 \mathrm{~m}$ ) and $\mathrm{Al}$ Ain (Latitude: $24^{\circ} 16^{\prime} \mathrm{N}$, Longitude: $55^{\circ} 36^{\prime} \mathrm{E}$, and Elevation: $250 \mathrm{~m}$ ) were obtained from the National Center of Meteorology and Seismology (Abu Dhabi, UAE). The obtained weather data includes measured daily global solar radiation on horizontal and daily sun hours for an observation period of 13 years.

The proposed regression models (Table 1) are the linear Angstrom-Prescott model, which is considered the most commonly used model $[3,4]$. The second model is the Akinoglu and Ecevit regression model, which is a correlation between $K_{T}$ and $R_{S}$ in a second-order (quadratic) polynomial [11]. Samuel suggested the third regression model, which represents a third-order correlation [12]. Ampratwum and Dorvlo proposed the fourth used regression model, which is a logarithmic correlation between $K_{T}$ and $R_{S}$ [13]. The fifth model was suggested by Newland, which represents a linear-logarithmic correlation equation [14]. The sixth (exponential) and seventh (power) regression models were proposed by Elagib \& Monsell and Coppolino, respectively $[15,16]$. Correlation coefficient values were calculated from the regression analysis between $K_{T}$ and $R_{S}$ in a daily and monthly basis as proposed by Tadros in Egypt [17].

MATLAB was used to compute the coefficients and to compare between the seven regression models statistically in order to find the best predictive model. Number of statistical methods was used to validate the accuracy and goodness of the fits. These methods included the residual analysis and goodness of fits statistics, such as the coefficient of determination $\left(R^{2}\right)$, mean absolute percentage error 
TABLE 2: Correlation coefficients.

\begin{tabular}{|c|c|c|c|c|c|}
\hline Station & Model & $a$ & $b$ & $c$ & $d$ \\
\hline \multirow{7}{*}{ Abu Dhabi } & Linear & 0.1833 & 0.5301 & & \\
\hline & Quadratic & 0.1890 & 0.8450 & -0.3900 & \\
\hline & Cubic & 0.4201 & 0.5292 & -0.7771 & 0.5211 \\
\hline & Exponential & 0.5399 & 0.1630 & & \\
\hline & Logarithmic & 0.6290 & 0.1053 & & \\
\hline & $\begin{array}{l}\text { Linear- } \\
\text { logarithmic }\end{array}$ & 0.7621 & -0.16268 & 0.08576 & \\
\hline & Power & -0.4698 & 0.034 & & \\
\hline \multirow{7}{*}{$\mathrm{Al}$ Ain } & Linear & 0.1833 & 0.6478 & & \\
\hline & Quadratic & 0.6351 & 0.0966 & -0.0255 & \\
\hline & Cubic & 0.4411 & 0.8292 & -0.9771 & 0.4211 \\
\hline & Exponential & 0.6416 & 0.099 & & \\
\hline & Logarithmic & 0.6858 & 0.0153 & & \\
\hline & $\begin{array}{l}\text { Linear- } \\
\text { logarithmic }\end{array}$ & 0.7081 & -0.01268 & 0.01276 & \\
\hline & Power & -0.4058 & 0.00014 & & \\
\hline
\end{tabular}

TABLE 3: Goodness of fit statistics for the used regression models.

\begin{tabular}{llccccccc}
\hline Station & Model & $R^{2}$ & MAPE & MBE & MABE & RMSE & SSR & SST \\
\hline \multirow{5}{*}{ Abu Dhabi } & $94 \%$ & 1.89 & -0.0035 & 0.1080 & 0.1330 & 17.751 & 18.862 \\
& Linear & $90 \%$ & 1.94 & 0.0094 & 0.1162 & 0.1529 & 16.979 & 18.863 \\
& Quadratic & $91 \%$ & 1.75 & 0.0006 & 0.1038 & 0.1324 & 17.209 & 18.861 \\
& Cubic & $88 \%$ & 2.23 & 0.0370 & 0.1338 & 0.1742 & 16.628 & 18.878 \\
& Logponential & $88 \%$ & 2.39 & 0.0148 & 0.1410 & 0.1777 & 16.687 & 18.864 \\
& Linear-logarithmic & $87 \%$ & 3.11 & 0.0151 & 0.1799 & 0.2141 & 16.449 & 18.864 \\
& Power & $88 \%$ & 2.52 & 0.0077 & 0.1474 & 0.1825 & 16.682 & 18.862 \\
\hline \multirow{5}{*}{ Al Ain } & Linear & $81 \%$ & 3.39 & -0.1341 & 0.1751 & 0.2173 & 16.328 & 20.766 \\
& Quadratic & $83 \%$ & 3.15 & -0.0068 & 0.1935 & 0.2134 & 16.610 & 19.919 \\
& Cubic & $83 \%$ & 3.06 & 0.0016 & 0.1881 & 0.2078 & 16.497 & 19.918 \\
& Exponential & $81 \%$ & 3.32 & 0.0053 & 0.2142 & 0.2592 & 16.166 \\
& Logarithmic & $84 \%$ & 3.45 & 0.1040 & 0.2131 & 0.2332 & 16.794 & 20.048 \\
& Linear-logarithmic & $83 \%$ & 3.07 & -0.0059 & 0.1896 & 0.2104 & 16.505 \\
& Power & $74 \%$ & 4.10 & 0.2658 & 0.2781 & 0.3685 & 15.351 \\
\hline
\end{tabular}

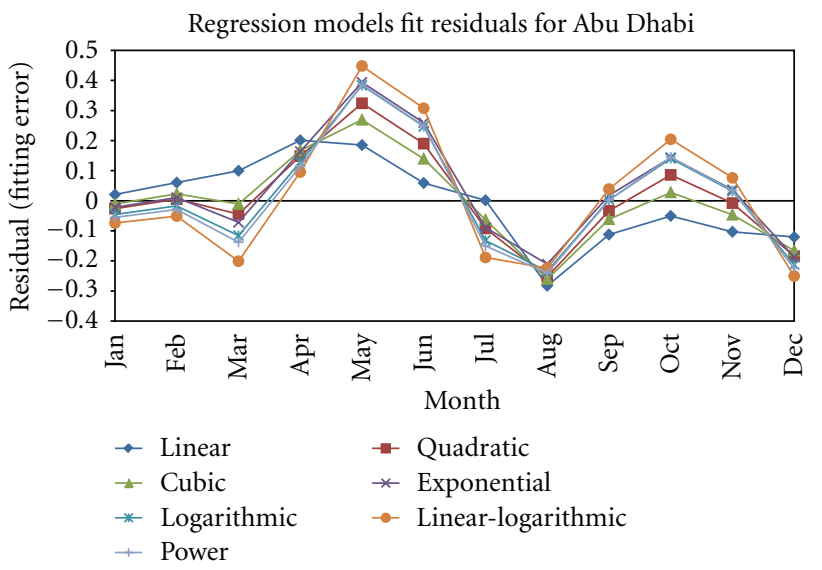

Figure 2: Residual analysis for Abu Dhabi.

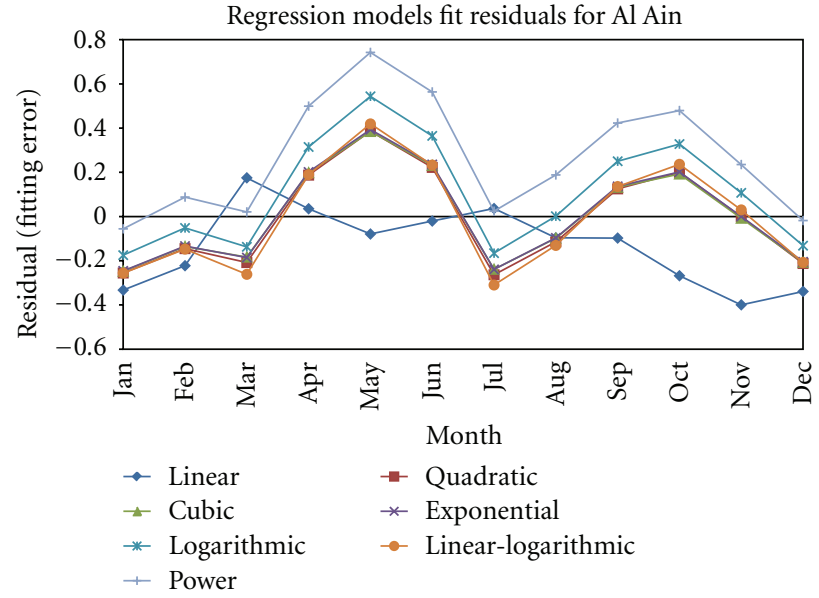

FIgURE 3: Residual analysis for Al-Ain. 

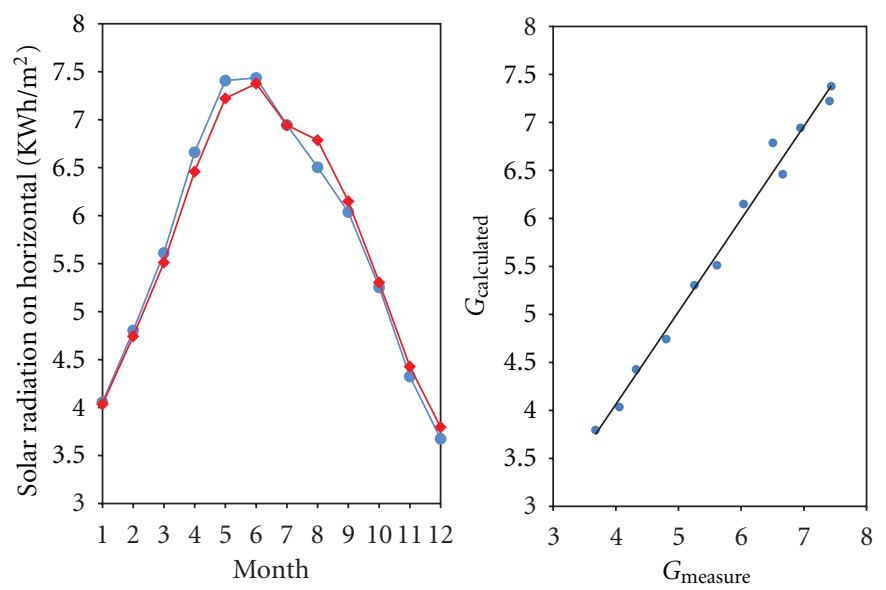

$\rightarrow$ Measured

$\rightarrow \quad$ Linear model

(a)
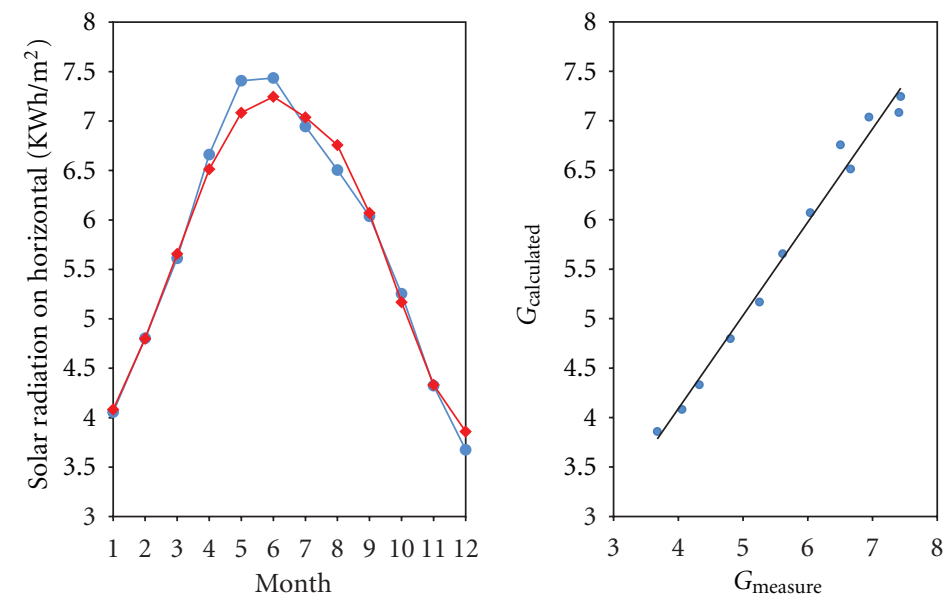

- - Measured

$\rightarrow$ Quadratic model

(b)
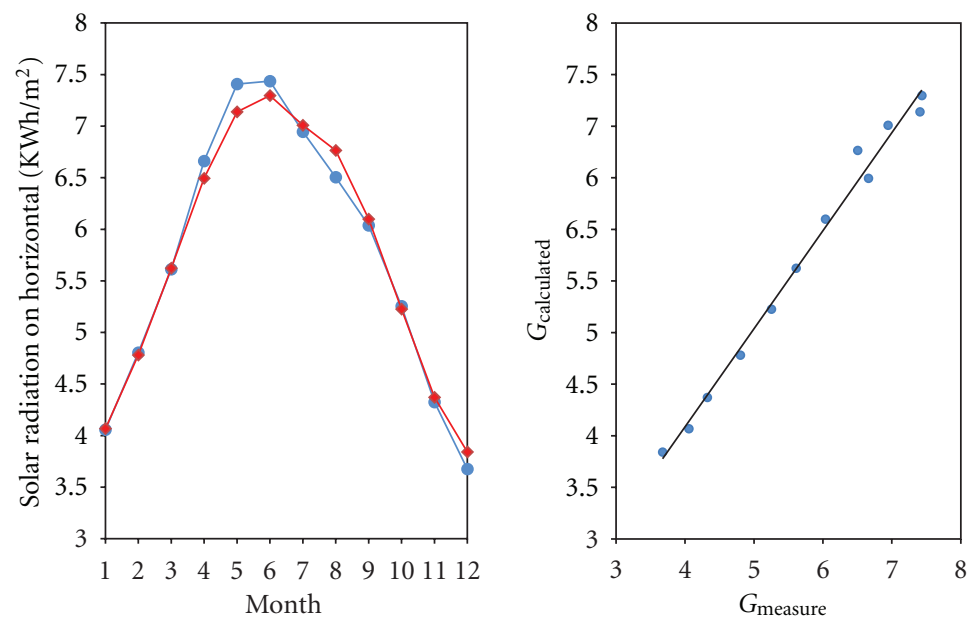

- - Measured

$\rightarrow$ Cubic model

(c)

Figure 4: Continued. 

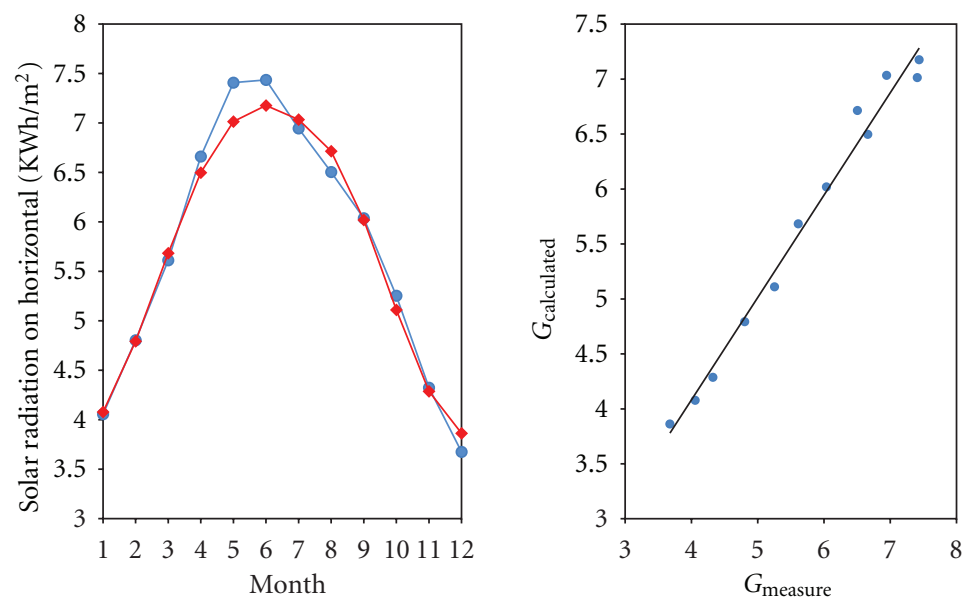

$\rightarrow$ Measured

$\multimap$ Exponential model

(d)
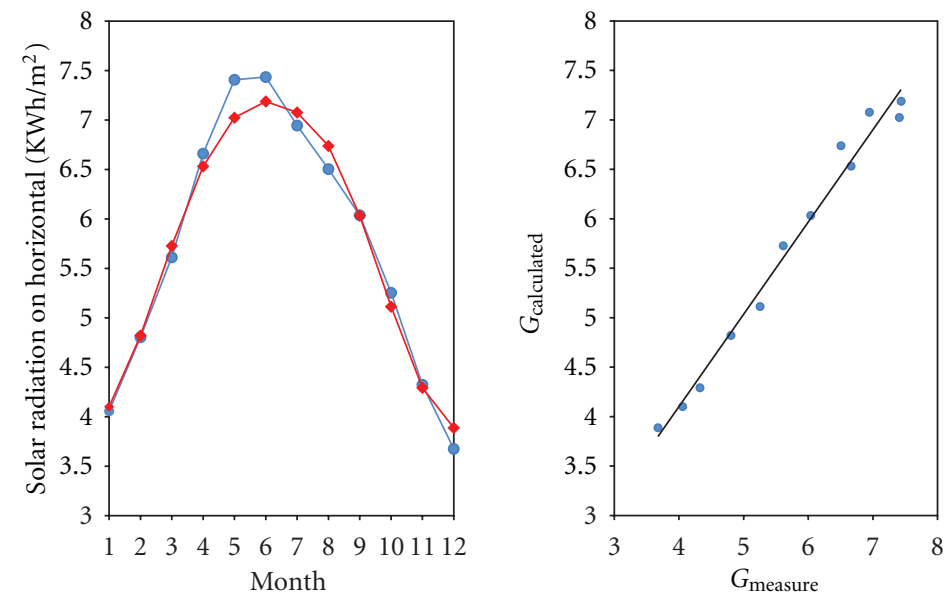

$\rightarrow$ Measured

$\rightarrow$ Logarithmic model

(e)
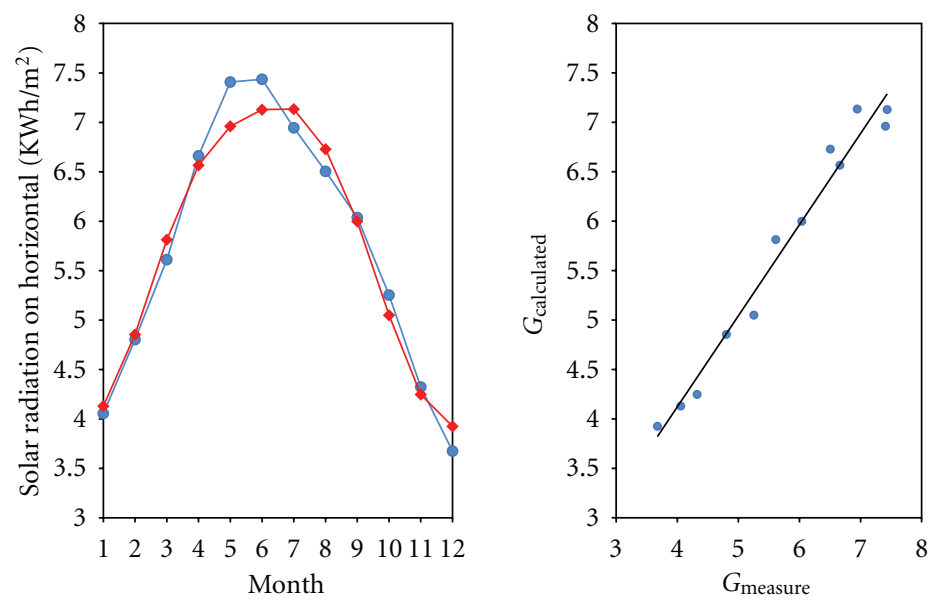

$\multimap-$ Measured

$\multimap$ Linear-logarithmic model

(f)

FIgure 4: Continued. 

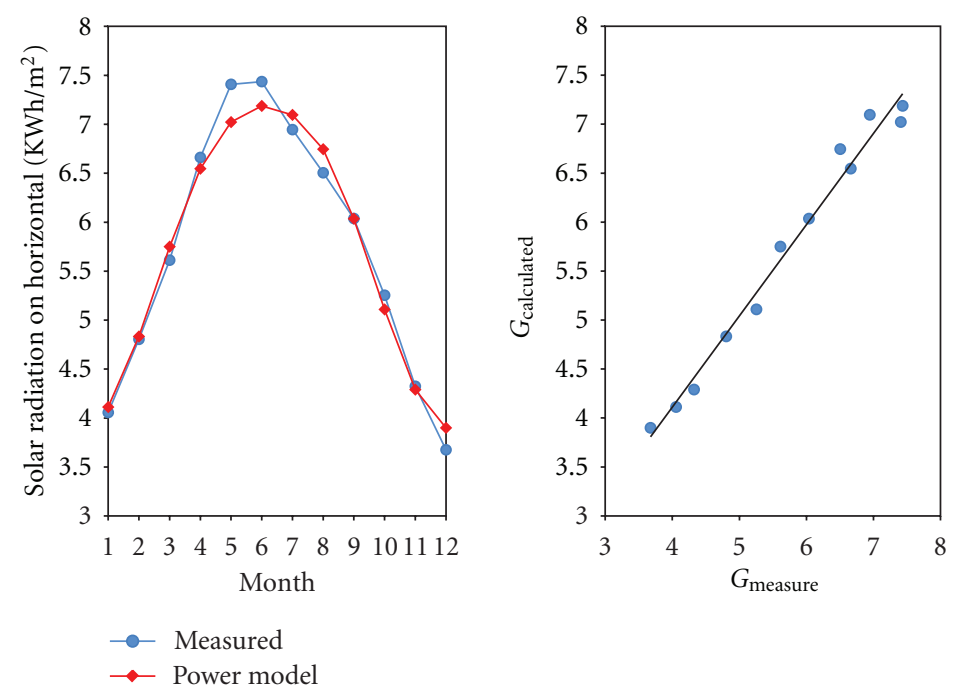

(g)

Figure 4: (a-g) Comparison between the measured and the calculated values of the monthly average daily global solar radiation using seven different regression models for Abu Dhabi, UAE.

(MAPE), root mean square error (RMSE), mean bias error (MBE), and mean absolute bias error (MABE). The residuals from a fitted model are defined as the differences between the response data and the fit to the response data at each predictor value. Assuming the model fitted to the data is correct, the residuals approximate the random errors. Therefore, if the residuals appear to behave randomly, it suggests that the model fits the data well. However, if the residuals display a systematic pattern, it will be a clear sign that the model poorly fits the data [18].

Equation (5) shows how to calculate MAPE of the fit, which is a measure of the forecast accuracy. MBE gives information on the long-term performance. A positive MBE shows an overestimation while a negative $\mathrm{MBE}$ represents an underestimation (6) [7]. The MABE is a measure of the goodness of the fit used to produce the models (7). RMSE gives information on the short-term performance of the correlations (8) [18]. Low values of MAPE, MBE, MABE, and RMSE are always required;

$$
\begin{array}{r}
\text { MAPE }=\frac{1}{n} \sum_{i=1}^{n}\left(\left|\frac{G_{m}^{i}-G_{c}^{i}}{G_{m}^{i}}\right| \times 100\right), \\
\text { MBE }=\frac{\sum_{i=1}^{n}\left(G_{m}^{i}-G_{c}^{i}\right)}{n}, \\
\text { MABE }=\frac{\sum_{i=1}^{n}\left(\left|G_{m}^{i}-G_{c}^{i}\right|\right)}{n}, \\
\text { RMSE }=\sqrt{\frac{\sum_{i=1}^{n}\left(G_{m}^{i}-G_{c}^{i}\right)^{2}}{n}}
\end{array}
$$

where $G_{m}$ and $G_{c}$ represent the measured and calculated monthly global solar radiation on horizontal. The coefficient of determination $\left(R^{2}\right)$ measures how successful the fit is in explaining the variation of the data, which can be calculated using (9). SST and SSR are the total sum of squares and the sum of squares of the regression, respectively,

$$
\begin{gathered}
R^{2}=\frac{\mathrm{SSR}}{\mathrm{SST}}, \\
\mathrm{SSR}=\sum_{i=1}^{n}\left(\overline{G_{m}}-G_{c}^{i}\right)^{2}, \\
\mathrm{SST}=\sum_{i=1}^{n}\left(\overline{G_{m}}-G_{m}^{i}\right)^{2}, \\
\overline{G_{m}}=\frac{1}{n} \sum_{i=1}^{n} G_{m}^{i} .
\end{gathered}
$$

\section{Results and Discussion}

The coefficients of the seven regression models used in this work are reported in Table 2. The statistical results of the corresponding models are given in Table 3. As mentioned earlier, it is preferred to have the statistics like MAPE, MABE, and RMSE as small as possible (i.e., close to zero).

The residual analysis showed that the fitting error for the developed models are scattered randomly around zero, which indicates a good fit as illustrated in Figures 2 and 3. However, as it can be observed from Figure 3, the regression models for Al Ain produced a slightly greater fitting errors compared to those for Abu Dhabi. The lowest coefficient of determination was $74 \%$. Abu Dhabi data produced a generally better fits than that of $\mathrm{Al}$ Ain, with a minimum $R^{2}$ of $87 \%$. The logarithmic (Ampratwum and Dorvlo) regression model offered the best estimate with the highest coefficient of determination value $\left(R^{2}=84 \%\right)$ for Al Ain. While the linear Angstrom-Prescott model performed best $\left(R^{2}=94 \%\right)$ 

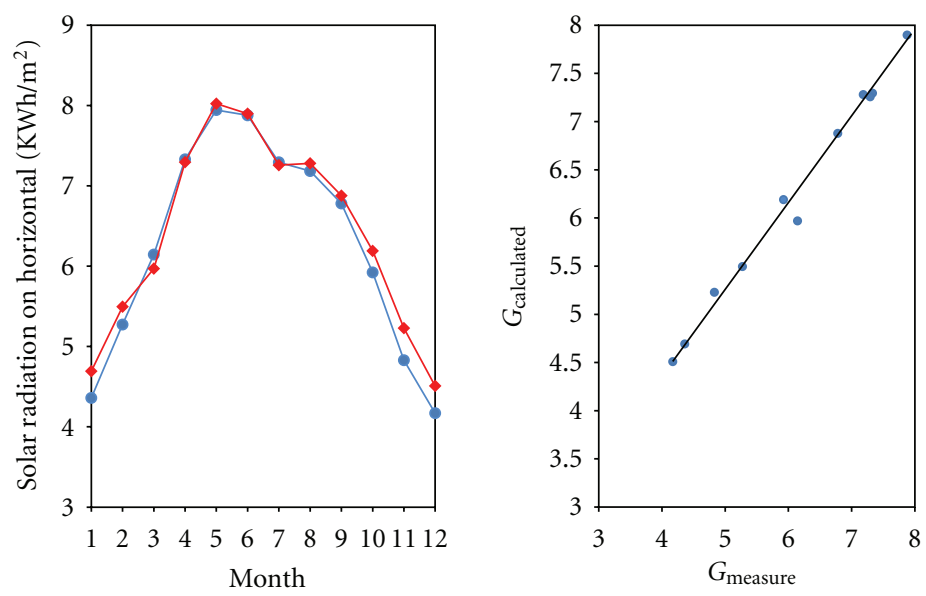

- Measured

$\rightarrow$ Linear model

(a)
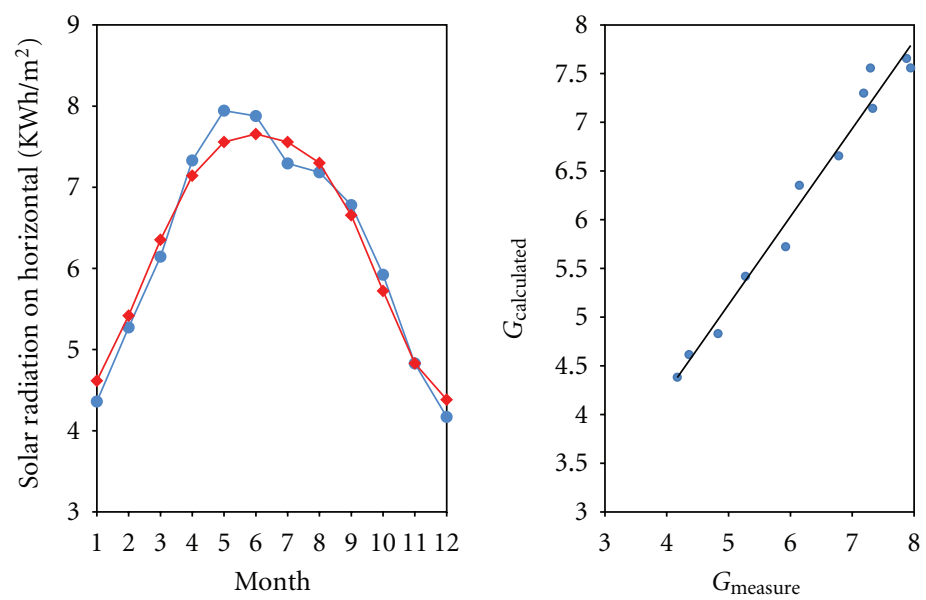

- Measured

$\rightarrow$ Quadratic model

(b)
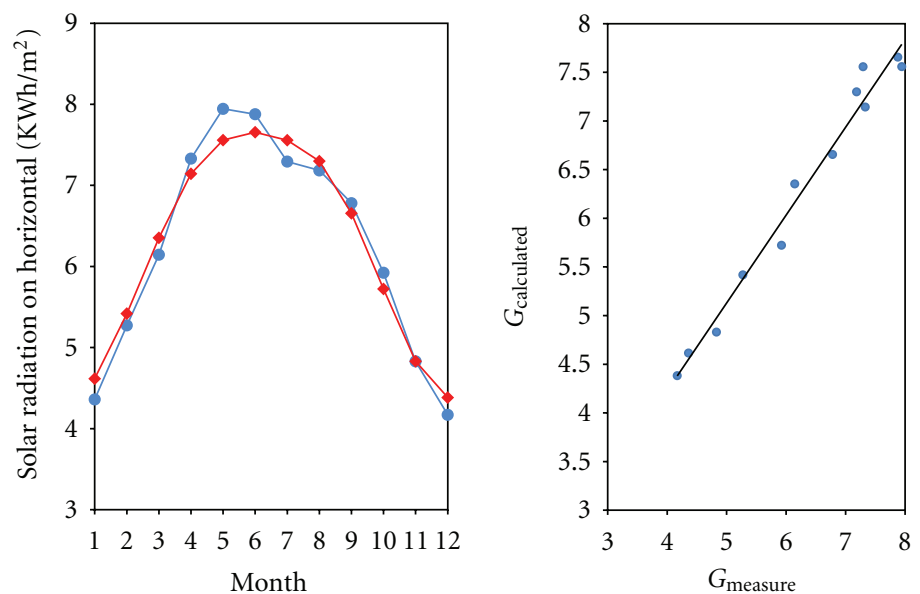

- - Measured

$\rightarrow$ Quadratic model

(c)

Figure 5: Continued. 

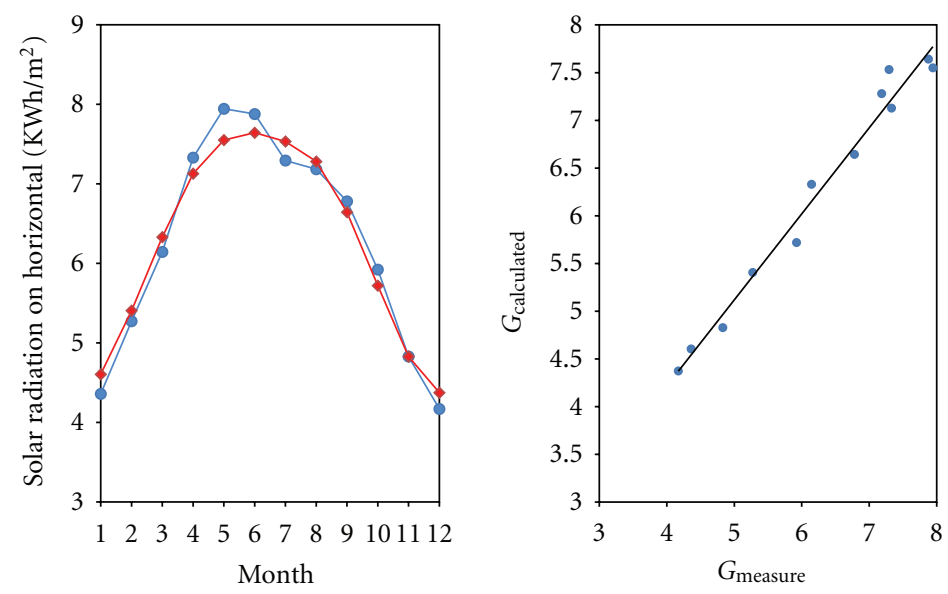

- - Measured

$\rightarrow-$ Exponential model

(d)
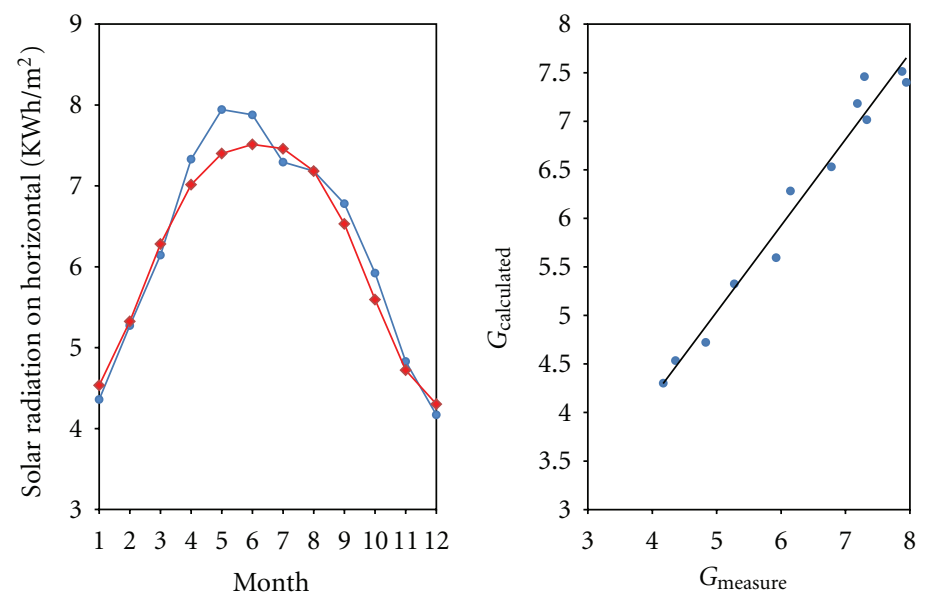

$\rightarrow$ Measured

$\multimap$ Logarithmic model

(e)
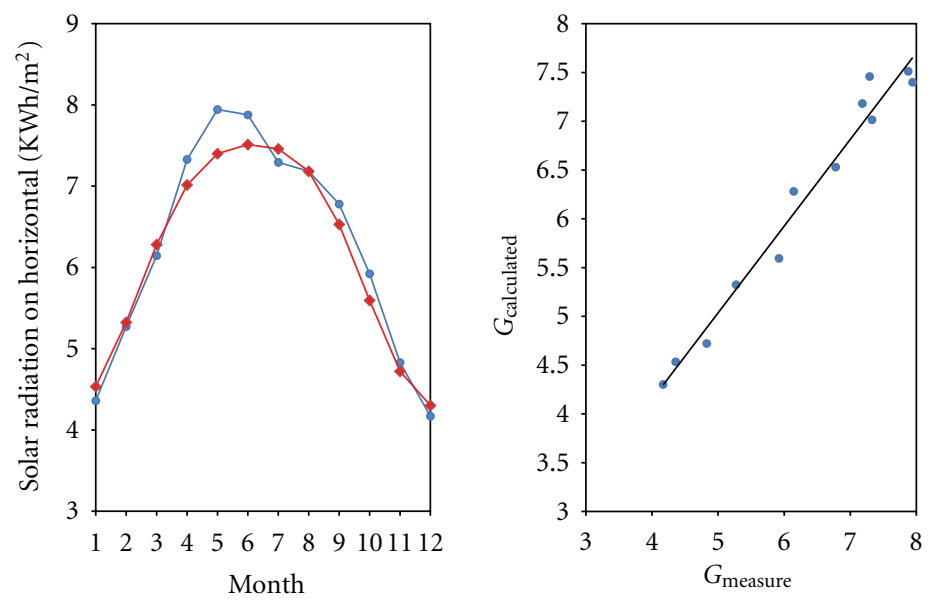

$\rightarrow$ Measured

$\rightarrow$ Logarithmic model

(f)

Figure 5: Continued. 

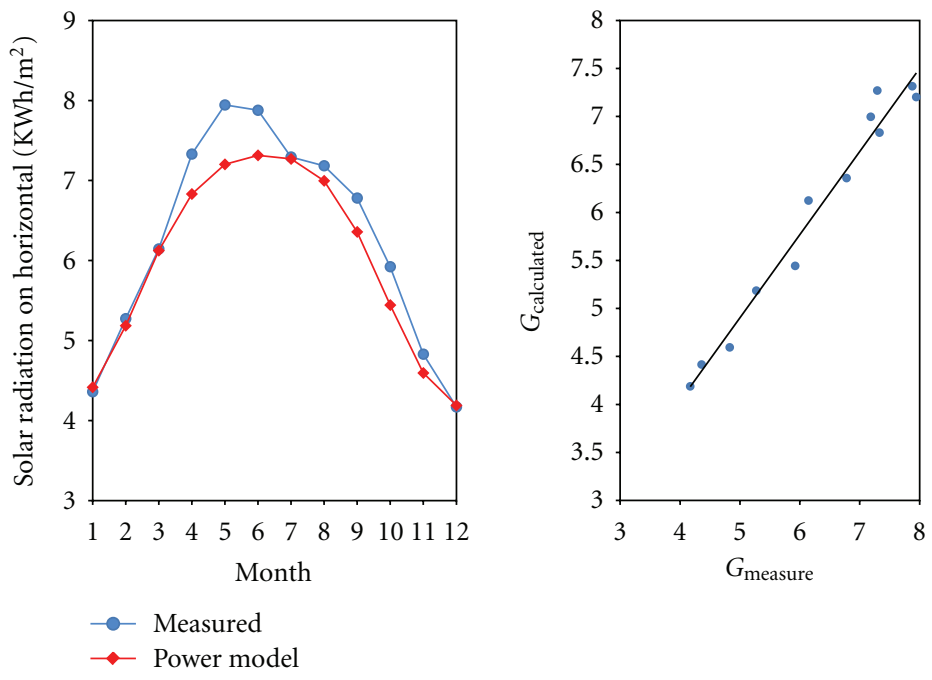

(g)

Figure 5: (a-g) Comparison between the measured and the calculated values of the monthly average daily global solar radiation using seven different regression models for Al-Ain, UAE.

for Abu Dhabi. The power (Coppolino) model performed worse overall in $\mathrm{Al}$ Ain, giving the lowest coefficient of determination $\left(R^{2}\right)$ value of $74 \%$ and the highest values of MAPE, MABE, and RMSE. The quadratic, third-order, and exponential regression equations offered good and almost similar statistic results for $\mathrm{Al}$ Ain.

Regarding RMSE values, all models resulted in very small values of RMSE for both cities of Abu Dhabi and Al Ain. The cubic model (Samuel) gave the smallest MAPE for Abu Dhabi and $\mathrm{Al}$ Ain, 1.75 and 3.06, respectively.

The regression coefficients obtained for Abu Dhabi are different than those of $\mathrm{Al} \mathrm{Ain.} \mathrm{The} \mathrm{variations} \mathrm{between} \mathrm{the}$ measured data of monthly average daily global radiation for Abu Dhabi and $\mathrm{Al}$ Ain and its calculated counterparts for the seven different regression models are shown in Figures 4 and 5 .

It is obvious that all regression models except the power (Coppolino) model performed almost with the same degree of accuracy in $\mathrm{Al} \mathrm{Ain.} \mathrm{In} \mathrm{order} \mathrm{to} \mathrm{come} \mathrm{up} \mathrm{with} \mathrm{a} \mathrm{more}$ accurate regression models, several estimators (models) can be used to predict the monthly average daily global radiation on horizontal across the year. For example, the power model performed very well in the winter months (Dec, Jan, Feb, and Mar) in Al Ain as shown in Figure 5, which are the months in which the third-order regression model performed poorly.

Regarding the MBE, underestimation of the solar radiation on horizontal for the linear Angstrom-Prescott model was noted in both cities of Abu Dhabi and Al Ain. A negative value gives the average amount of underestimation in the predicted values and vice versa. The third-order model offered the lowest values of MBE compared to the other used models in both Abu Dhabi and Al-Ain stations, 0.0006 and 0.0016 , respectively. Also the third-order model performed best regarding RMSE for both stations, with approximately 0.1324 in Abu Dhabi and 0.2078 in Al-Ain.
It can be noted that all regression models in Al-Ain failed to provide a value of $R^{2}$ better than $84 \%$, which was obtained using the logarithmic model. Since almost all regression models in Al-Ain station performed closely in terms of the value of $R^{2}$ except the power (Coppolino) model, the thirdorder model was chosen to be the best estimator model in terms of the other statistical tests such as MBE, MAPE, RMSE, and MABE.

\section{Conclusion}

Many regression models that estimate global solar radiation using more readily meteorological data were proposed in literature. A number of sunshine duration regression models have been studied and analyzed to estimate monthly average daily global solar radiation on horizontal in both cities of Abu Dhabi and Al Ain, UAE. In general, all models performed well with minimum $R^{2}$ of $74 \%$ given by the power (Coppolino) model in Al Ain. It was found that the linear Angstrom-Prescott model performed the best overall by the means of $R^{2}$ (94\%) in Abu Dhabi. While the logarithmic model offered the best estimate in $\mathrm{Al}$ Ain, other models also offered almost similar accuracy except for the power model. In order to improve the accuracy of the estimation, multiple estimators can be used to predict the average monthly global solar radiation on horizontal across the year.

\section{Abbreviations}

$G_{\text {sc }}:$ Solar constant $\left(\mathrm{W} / \mathrm{m}^{2}\right)$

$\Phi$ : $\quad$ Site latitude (deg)

$\Delta: \quad$ Solar declination angle (deg)

$\omega_{s}$ : Sun rise hour (deg)

$G$ : Global solar radiation on horizontal $\left(\mathrm{kWh} / \mathrm{m}^{2}\right)$ 
$G_{o}: \quad$ Extraterrestrial radiation $\left(\mathrm{Wh} / \mathrm{m}^{2}\right)$

$d_{n}$ : Number of the day in the year

$K_{T}$ : $\quad$ Clearness index

S: $\quad$ Monthly average daily sun hours (h)

$S_{0}$ : Monthly average maximum possible

daily sun hours (h)

$R_{S}: \quad$ The sunshine hours ratio

$R^{2}$ : $\quad$ Coefficient of determination $\left(\mathrm{kWh} / \mathrm{m}^{2}\right)$

$G_{m}$ : Measured monthly global solar

radiation on horizontal $\left(\mathrm{kWh} / \mathrm{m}^{2}\right)$

$G_{c}$ : Calculated monthly global solar

radiation on horizontal $\left(\mathrm{kWh} / \mathrm{m}^{2}\right)$

$n: \quad$ Number of samples

MAPE: Mean absolute percentage error $\left(\mathrm{kWh} / \mathrm{m}^{2}\right)$

RMSE: Root mean square error $\left(\mathrm{kWh} / \mathrm{m}^{2}\right)$

MABE: Mean absolute bias error $\left(\mathrm{kWh} / \mathrm{m}^{2}\right)$

MBE: Mean bias error $\left(\mathrm{kWh} / \mathrm{m}^{2}\right)$

SSR: Sum of squares of the regression $\left(\mathrm{kWh} / \mathrm{m}^{2}\right)$

SST: Total sum of squares $\left(\mathrm{kWh} / \mathrm{m}^{2}\right)$.

\section{Acknowledgments}

The authors would like to thank the National Center of Meteorology and Seismology (Abu Dhabi) for providing weather data. This work was financially supported by the UAE University under the Contract no. 07-04-7-11/09.

\section{References}

[1] J. Almorox and C. Hontoria, "Global solar radiation estimation using sunshine duration in Spain," Energy Conversion and Management, vol. 45, no. 9-10, pp. 1529-1535, 2004.

[2] H. O. Menges, C. Ertekin, and M. H. Sonmete, "Evaluation of global solar radiation models for Konya, Turkey," Energy Conversion and Management, vol. 47, no. 18-19, pp. 31493173, 2006.

[3] A. Angstrom, “'Solar and terrestrial radiation', report to the international commission for solar research on actinometric investigations of solar and atmospheric radiation," Quarterly Journal of the Royal Meteorological Society, vol. 50, no. 210, pp. 121-126, 1924.

[4] J. A. Prescott, "Evaporation from water surface in relation to solar radiation," Transactions and Proceedings of Royal Society of South Australia, vol. 64, no. 1, pp. 114-118, 1940.

[5] S. K. Srivastava, A. Gaur, O. P. Singh, and R. N. Tiwari, "Comparison of methods for estimating daily and hourly diffuse solar radiation," Applied Energy, vol. 51, no. 2, pp. 119123,1995

[6] K. Bakirci, "Correlations for estimation of daily global solar radiation with hours of bright sunshine in Turkey," Energy, vol. 34, no. 4, pp. 485-501, 2009.

[7] Z. Jin, W. Yezheng, and Y. Gang, "General formula for estimation of monthly average daily global solar radiation in China," Energy Conversion and Management, vol. 46, no. 2, pp. 257-268, 2005.

[8] A. El- Sebaii and A. Trabea, "Estimation of global solar radiation on horizontal surfaces over Egypt," Egyptian Journal of Solids, vol. 28, no. 1, 2005.
[9] A. Assi, M. Al-Shamisi, and M. Jama, "Prediction of monthly average daily global solar radiation in $\mathrm{Al}$ Ain City-UAE using artificial neural networks," in Proceedings of the 25th European Photovoltaic Solar Energy Conference, Valencia, Spain, 2010.

[10] A. Luque and S. Hedgus, Handbook of Photovoltaic Science and Engineering, John Wiley \& Sons, Chichester, UK, 1st edition, 2005.

[11] B. G. Akinoglu and A. Ecevit, "A further comparison and discussion of sunshine-based models to estimate global solar radiation," Energy, vol. 15, no. 10, pp. 865-872, 1990.

[12] T. D. M. A. Samuel, "Estimation of global radiation for Sri Lanka," Solar Energy, vol. 47, no. 5, pp. 333-337, 1991.

[13] D. B. Ampratwum and A. S. S. Dorvlo, "Estimation of solar radiation from the number of sunshine hours," Applied Energy, vol. 63, no. 3, pp. 161-167, 1999.

[14] F. J. Newland, "A study of solar radiation models for the coastal region of South China," Solar Energy, vol. 43, no. 4, pp. 227235, 1989.

[15] N. A. Elagib and M. G. Mansell, "New approaches for estimating global solar radiation across Sudan," Energy Conversion and Management, vol. 41, no. 5, pp. 419-434, 2000.

[16] S. Coppolino, "A new correlation between clearness index and relative sunshine," Renewable Energy, vol. 4, no. 4, pp. 417423, 1994.

[17] M. T. Y. Tadros, "Uses of sunshine duration to estimate the global solar radiation over eight meteorological stations in Egypt," Renewable Energy, vol. 21, no. 2, pp. 231-246, 2000.

[18] A. Al-Lawati, A. S. S. Dorvlo, and J. A. Jervase, "Monthly average daily solar radiation and clearness index contour maps over Oman," Energy Conversion and Management, vol. 44, no. 5, pp. 691-705, 2003. 

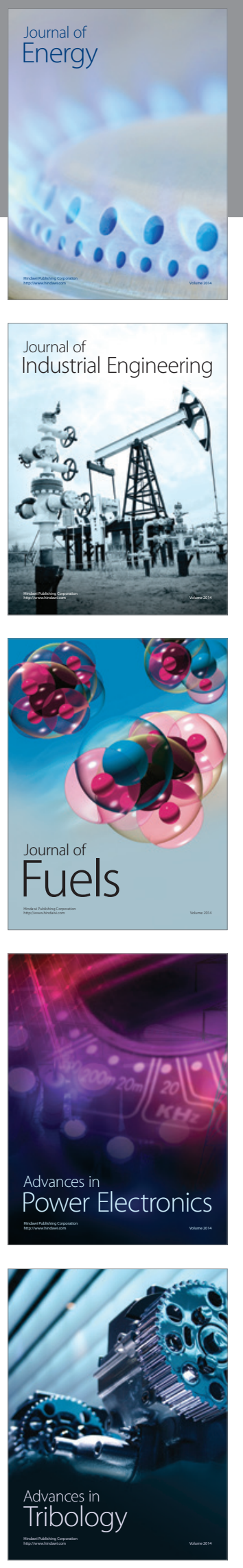
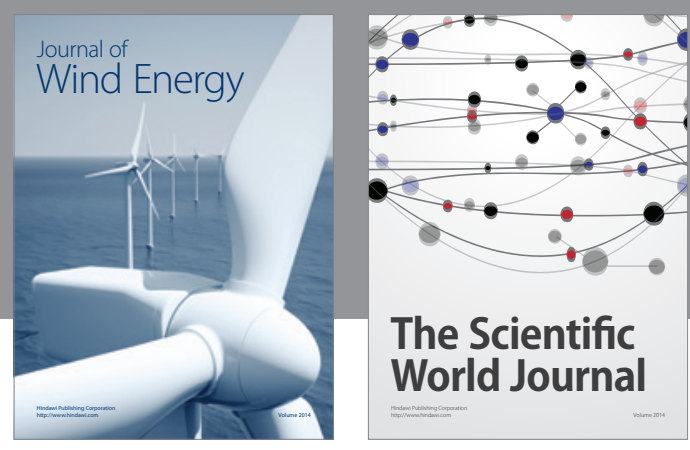

The Scientific World Journal

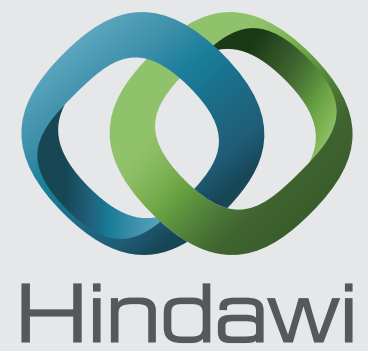

Submit your manuscripts at http://www.hindawi.com
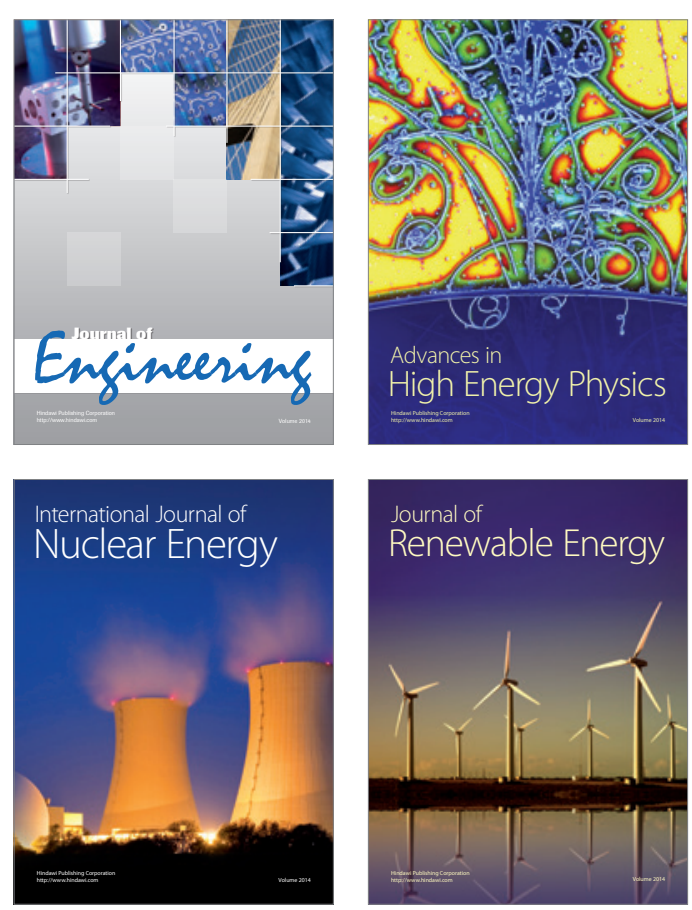

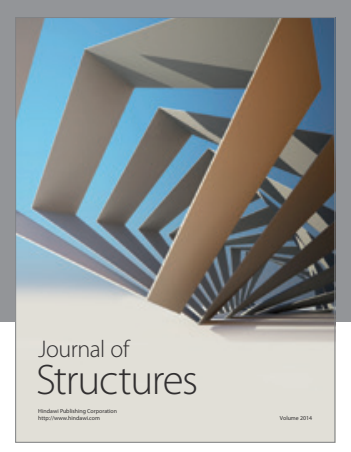

Rotating
Mechinery
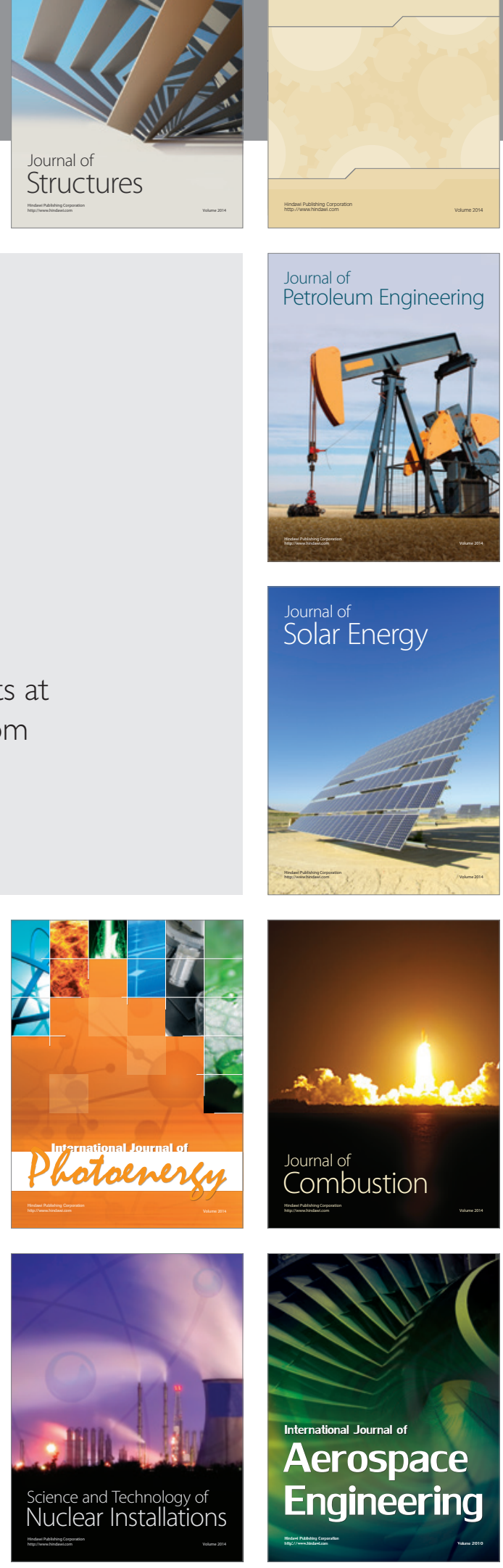